\begin{tabular}{|l|l|l||}
\hline \multicolumn{2}{|c|}{ PublisherInfo } \\
\hline \hline PublisherName & $:$ & BioMed Central \\
\hline \hline PublisherLocation & $:$ & London \\
\hline \hline PublisherImprintName & $:$ & BioMed Central \\
\hline \hline
\end{tabular}

\title{
VEGF and radiotherapy in node-negative breast cancer
}

\begin{tabular}{||l|l|l||}
\hline \multicolumn{2}{|c||}{ ArticleInfo } \\
\hline \hline ArticleID & $:$ & 3661 \\
\hline \hline ArticleDOI & $:$ & $10.1186 /$ bcr-1999-66639 \\
\hline \hline ArticleCitationID & $:$ & 66639 \\
\hline \hline ArticleSequenceNumber & $:$ & 27 \\
\hline \hline ArticleCategory & $:$ & Paper Report \\
\hline ArticleFirstPage & $:$ & 1 \\
\hline \hline ArticleLastPage & $:$ & 4 \\
\hline \hline & & RegistrationDate : 1999-11-11 \\
ArticleHistory & $:$ & OnlineDate $:$ 1999-11-11 \\
\hline \hline ArticleCopyright & $:$ & Current Science Ltd1999 \\
\hline \hline ArticleGrants & $:$ & \\
\hline \hline ArticleContext & $:$ & 1305822 \\
\hline \hline
\end{tabular}




\section{Keywords}

Node-negative breast cancer, radiotherapy, relapse, survival, VEGF

\section{Introduction}

Patients with node-negative breast cancer (NNBC) often receive postoperative adjuvant radiotherapy as a means of eradicating any micrometastatic deposits which may still remain in the breast following surgical resection. However, approximately one third of these patients relapse and a subgroup shows increased morbidity or reduced survival. There is a need to define other criteria in these patients which could be used to optimise treatment. The angiogenic factor, vascular endothelial growth factor (VEGF), correlates with tumour vascularity and has been proposed as a predictor of overall survival (OS) in breast cancer patients. The degree of tumour vascularity may also be important for effective radiotherapy; this is thought to be less effective in poorly vascularised tumours.

\section{Aims}

To determine the association of VEGF content in breast tumours from node-negative patients treated with postoperative locoregional radiotherapy with relapse free survival (RFS) and overall survival (OS).

\section{Comments}

The importance of VEGF in breast cancer biology is now becoming evident. The high VEGF expression seen in NNBC could be associated with a radioresistant phenotype or be indicative of early metastatic spread. Measurement of VEGF in this patient cohort may identify individuals with a high risk of recurrence or death, and impact on choice of therapy at an earlier stage of the disease.

\section{Methods}


Tumour samples were obtained from 302 patients who presented with NNBC without detectable metastasis. The median age was 56 years and the median follow-up time was 56 months. Following surgical resection, patients received daily radiotherapy (2-Gy fractions delivered 5 days per week to a total dose of 56 Gy). No patients received any additional systemic therapy.

Frozen tumour samples were homogenised and analysed for VEGF using an immunoassay kit which detects VEGF 165, the predominant secreted isoform. Tumour oestrogen receptor (ER) and progesterone receptor (PR) content was determined using an enzyme immunoassay.

\section{Results}

A wide variation in VEGF levels was detected (median value $1.92 \mathrm{pg} / \tilde{\mathrm{A}} \check{Z} \mathrm{~A}{ }^{1} / \mathrm{g} \mathrm{g}$ DNA, range 0.01-144.79). VEGF was significantly associated with established prognostic indicators including ER, PR and tumour size, and a borderline association was observed with tumour grade. No associations were observed between VEGF content and histological type or patient age.

In total, 43 patients relapsed (10 in-breast failures, 5 lymph node and 28 distant metastases). Of these patients, there was no statistical correlation between VEGF content and localisation of the relapse.

Univariate analysis showed a reduced RFS and OS in patients with tumours with high VEGF content. Additionally, tumour size and grade were associated with RFS, while ER status, tumour type or patient age were not. Multivariate analysis showed VEGF to be the only valid predictor of OS; patients with tumours containing high levels of VEGF had a 3.62-fold increased risk of death compared with those with low VEGF. In T1 tumours or ER-positive tumours, VEGF could predict both RFS and OS.

\section{Discussion}

Although the use of the angiogenic factor VEGF is gaining support as a prognostic factor in many types of cancer, the relationship between VEGF with regard to radiotherapy and RFS/OS has not previously been shown. The results presented here suggest VEGF could be of additional benefit as a predictor of RFS and OS, particularly in NNBC patients treated with radiotherapy. 


\section{References}

1. Linderholm B, Tavelin B, Grankvist K, Henriksson R: Does vascular endothelial growth factor (VEGF) predict local relapse and survival in radiotherapy-treated node-negative breast cancer?. Br J Cancer. 1999, 81: 727-732. 